\title{
Galectin Regulation of Host Microbial Interactions
}

\author{
Brian S. Robinson; Connie M. Arthur; Nourine A. Kamili; and Sean R. Stowell \\ Center for Transfusion Medicine and Cellular Therapies, Department of Laboratory Medicine and Pathology, \\ Emory University School of Medicine, Atlanta, GA \\ FAX: +1-404-727-8538, TEL: +1-404-727-7242, E-mail: srstowe@emory.edu
}

(Received on December 23, 2017, accepted on March 31, 2018)

Key Words: galectins, microbes, infection, immunity, glycans

\begin{abstract}
Galectins regulate a wide variety of biological processes. However, one of the earliest and most common galectin activities is likely their ability to recognize microbes. Galectin binding to microbes can result in direct microbial killing and activation of host immunity, eventually enhancing the ability of a host to eliminate microbes. However, microbes appear to have also evolved the ability to utilize galectins to enhance host attachment, ultimately leading to increased risk for infection. The ability of galectins to directly engage microbes, coupled with their role in regulating host immune function, positions these carbohydrate binding proteins as key factors that can dictate the consequence of microbial exposure. In this way, galectins represent a highly pleiotropic protein family involved in the regulation of a broad range of host-microbial interactions.
\end{abstract}

\section{A. Introduction}

Host pathogen interactions fundamentally shape a broad range of biological processes. While products of microbial metabolism can impact a wide variety of host activities, from neurological function to overall metabolism and immune homeostasis (1-3), direct interactions between host and microbes can fundamentally shape microbial flora, impact immune function and often ultimately dictate the likelihood of infectious disease (4). Although host factors can interact with a variety of distinct microbial molecular determinants, cell surface glycans represent the most unique, diverse and rich molecular features that decorate microbes $(5,6)$. As microbial carbohydrate determinants often completely envelope microbes, these structures often represent the first and most significant molecular signature encountered by a host. As a result, hosts appear to have evolved a variety of immune factors that possess the ability to recognize the distinct carbohydrate signature of a broad range of organisms (6-9). Indeed, many immune populations are defined by the distinct repertoire of glycan binding proteins (GBPs) they express (6-8), strongly suggesting that microbial glycan-host interactions may result in the engagement of specific immune cells and thus shape host immunity in fundamental ways.

\section{B. Discovery of Galectins}

Prior to studies that demonstrated the importance of host recognition of microbial glycans in shaping host immunity, the role of cell surface carbohydrates in general remained elusive for many years (10). However, subsequent studies began demonstrating that glycans can regulate a wide variety of fundamental biological processes (11-13). More specifically, the discovery of GBPs provided a potential mechanism of translating a cell surface glycan code into biologically meaningful outcomes (13). The discovery of mammalian GBPs also provided a mechanism whereby hosts may recognize and therefore respond to distinct microbes through recognition of their unique glycan determinants (5). Indeed, while the vast majority of early studies on GBP function focused primarily on GBP regulation of mammalian cell biology, the ability of GBPs to not only bind microbial glycans, but in some cases, exclusively recognize the glycan determinants of microbes, has become a focus GBP studies (5, 9, 14-19). While the microbial glycan specificity of many of these GBPs remains to be defined, GBP-microbial glycan interactions represent a fundamental aspect of host-microbial interactions.

Although the ability of plants to express GBPs was recognized in the 19th century, the potential existence of mammalian GBPs was actually quite controversial for many years. It wasn't until Ashwell and Morrell observed that desiaylated proteins were rapidly cleared in the liver that a potential mammalian GBP activity and therefore target was identified (20). Subsequent studies identified the potential receptor responsible for the removal of desialylated glycoproteins and in so doing characterized the asialoglycoprotein receptor $(21,22)$, the first example of a mammalian GBP. Despite the fact that the actual function of the asialoglycoprotein receptor would not be recognized until decades later (11), this discovery launched efforts by several labs to determine whether additional GBPs exist in vertebrates. Using similar biochemical approaches, in 1975 Teichberg and colleagues isolated the next vertebrate GBP described from the electric organ of the electric eel Electrophorus electricus (23). Coined electrolectin, the electric eel GBP was the first galectin discovered and was soon followed thereafter by similar proteins isolated by the laboratories of Bar- 


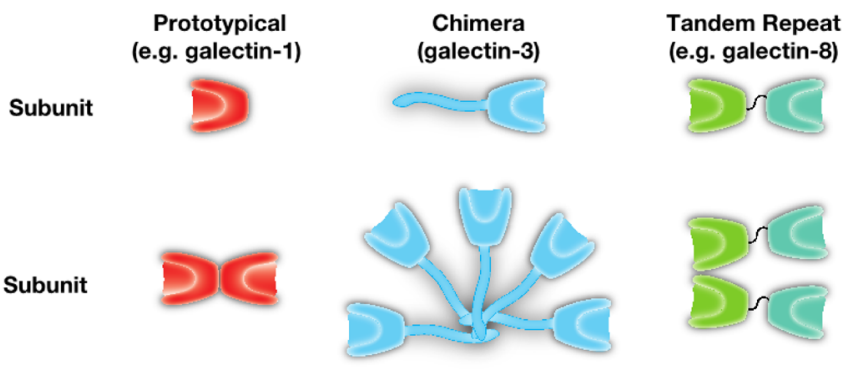

Fig. 1. The galectin family. Galectins are a family a $\beta$-galactoside binding proteins commonly classified into three groups: prototypical, chimeric and tandem repeat. Examples of human galectins within the prototypical subgroup include galectin-1, galectin-2, galectin-7, galectin-10, galectin-13 and galectin-14. Galectin-3 represents the chimeric galectin subgroup. Human tandem repeat galectins include galectin-4, galectin-8, galectin-9 and galectin-12.

ondes and Kornfeld from chicken and bovine sources, respectively (23-25). Currently, fifteen members of the galectin family (Gal-1 through -15) have been described in mammals (eleven in humans), ranging from 14-39 kDa in subunit size (26) (Fig. 1).

Although the discovery of galectins demonstrated that additional GBPs exist in mammals, the physiological role of galectins remained elusive for many years. The majority of early studies on galectins focused on the biochemical properties of galectin family members (27-36). These early studies demonstrated that galectins possess a common affinity for $\beta$-galactosides. In addition, several galectins appeared to exhibit a unique sensitivity toward oxidative inactivation (37-41). As a result, early nomenclature that defined mammalian GBPs originally categorized galectins as S-type lectins in an effort to emphasize their unique dependence on reduced thiols for activity (in contrast to C-type lectins, which require $\mathrm{Ca}^{2+}$ ) (27, 36, 42-44). As subsequent studies demonstrated that not all galectins exhibit sensitivity to oxidative inactivation, yet continued to share $\beta$-galactoside preferences $(45,46)$, the term galectins was used to describe a common feature of this protein family (47). Thus, while subsequent studies have demonstrated that individual galectin family members can exhibit very distinct glycan binding patterns $(28-30,48-50)$, galectins have historically consisted of a family of proteins characterized by an ability to bind $\beta$-galactosides.

\section{Galectins and Immunity}

In an effort to understand the function of galectins in vivo, early studies first examined galectin localization in tissue. While many of these studies demonstrated that galectins can exhibit differential expression during development, particularly within developing muscle tissue, several studies also demonstrated that galectin-1 exhibits significant localization within neuromuscular junctions (51-53). To determine whether exogenous administration of galectin-1 might favorably impact neuromuscular junction activity, Teichberg and colleagues employed a model of myasthenia gravis. Consistent with the potential involvement of galectin in the neuromuscular junction, injection of exogenous galectin-1 significantly improved muscle function. However, further investigation demonstrated that the ability of galectin-1 to alter muscle activity did not actually reflect direct alterations in neuromuscular endplate function, but instead resulted from the ability of galectin-1 to suppress the immune response needed to generate the myasthenia gravis model (54). Subsequent studies conducted by Offner and colleagues demonstrated that delivery of recombinant galectin-1 could also reduce adverse clinical sequelae in a model experimental autoimmune encephalomyelitis (55), a commonly employed model to study galectin function in later studies (56). Additional studies similarly demonstrated that administration of galectin-1 could positivity impact disease progression in models of hepatitis, colitis, nephritis and arthritis (57-60). These results suggested that galectin-1 in particular may regulate fundamental aspects of general immune function and provided some of the first insight into the biological roles of galectins in vivo. Many studies have now corroborated the notion that galectin-1 not only regulates immune function $(56,61,62)$, but that nearly every galectin family member possesses the ability to modify some aspect of immunity through engagement of a variety of cell types and through a broad range of mechanisms (35, 63-69).

While early studies examining galectin function primarily utilized models of autoimmunity, subsequent studies focused on the potential role of galectins in regulating immune responses following infectious challenge (70-72). These results suggested that galectins may serve as potent activators of innate immune cells and be critical in the orchestration of an effective adaptive immune response following microbial challenge (68). However, several studies also demonstrated that galectins might directly engage microbes (73-75), suggesting that galectins may more intimately regulate host response to microbial challenge. These results suggested that in addition to binding endogenous ligands, galectins may actually engage a variety of microbial carbohydrate determinants (5, 15-19). Furthermore, as galectins are soluble proteins, unlike most pattern recognition receptors with lectin activity that possess terminal carbohydrate recognition domains as part of a larger transmembrane protein, galectins appeared to be uniquely poised to directly engage microbes in a wide variety of settings (76). In this review, we will describe galectin interactions with potential pathogens by characterizing these interactions into broad categories, including examination of galectin interactions with bacteria, viruses, protozoa, trematodes, nematodes and fungi. In doing so, we will not 
provide an exhaustive review of the literature describing all known galectin-microbial interactions. Furthermore, while galectins regulate a wide variety of host immune factors with consequences on immune responsiveness to infectious challenge, we will not focus on aspects of galectin-mediated regulation of host immunity that impact the outcome of microbial exposure, which has been extensively reviewed elsewhere $(6,7,77)$. Instead, we will provide examples of galectin engagement of microbes that highlight the diverse nature and consequences that these interactions can have on host-microbial exposure.

\section{Galectin Interactions with Bacteria}

Despite significant interest in the potential roles galectins may play in the regulation of immune function, early studies also began examining the possible role of galectins to regulating host microbial interactions by directly engaging microbial glycans (78)

(Fig. 2). Early studies demonstrated that galectin-3 recognizes lipopolysaccharides (LPS) isolated from Klebsiella pneumoniae and Pseudomonas aeruginosa through carbohydrate dependent interactions $(73,74)$. Subsequent studies similarly demonstrated that galectin-3 could interact with the carbohydrate motifs of LPS isolated from Neisseria gonorrhoeae, Neisseria meningitidis and Helicobacter pylori (79-81). Importantly, examination of interactions between galectin-3 and $N$. meningitidis suggested that this interaction might be specific to galectin-3, as galectin-1 and galectin-4 failed to display similar binding in parallel studies. Furthermore, while interactions between galectin-3 and $N$. meningitidis LPS were inhibited by lactose, suggesting a carbohydrate-dependent binding event, galectin-3 engagement of $N$. meningitidis LPS required full-length galectin-3, as the carbohydrate recognition domain (CRD) alone of galectin-3 failed to display similar binding (80), suggesting that additional carbohydrate-independent interactions may occur. Consistent with this, galectin-3 interactions with LPS isolated from the Salmonella enterica ssp. S. enterica serovar S. minnesota R7 strain occurred through carbohydrate-independent interactions (73). Furthermore, although the CRD was responsible for the carbohydrate-dependent interactions observed between galectin-3 and the LPS of K. pneumoniae, the N-terminal, collagenlike domain was shown to be responsible for non-carbohydrate LPS interactions (73). These studies demonstrate that galectins can en-

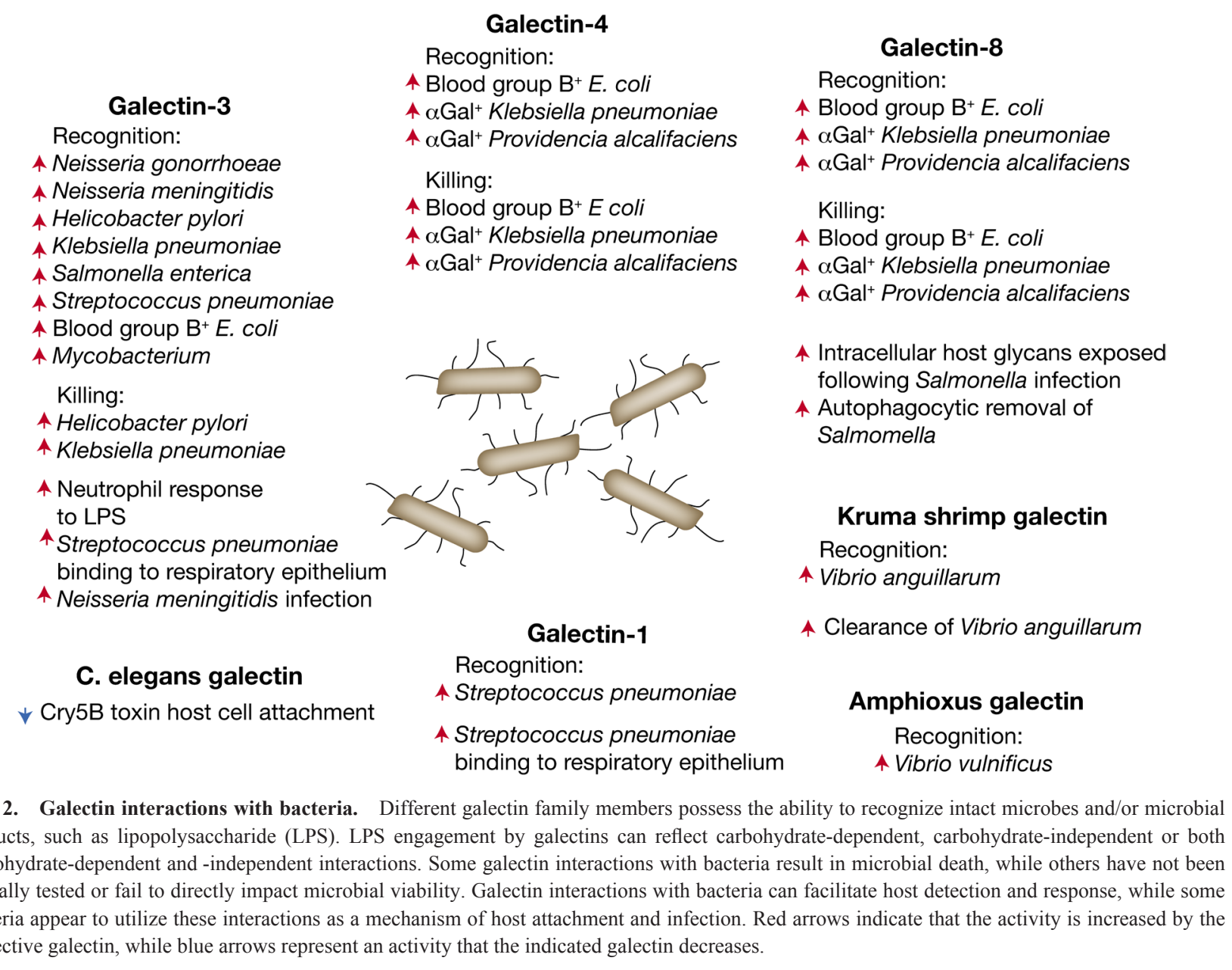


gage key molecular determinants of bacteria, but that these interactions may be more complex than simple carbohydrate recognition.

Although the molecular nature of galectin-3 binding with the non-carbohydrate lipid A portion of LPS remains incompletely defined, the ability of galectin-3 to specifically engage LPS suggested that galectin-3-LPS interactions may regulate key immune pathways. Indeed, several studies demonstrated that galectin-3 may not only interact with LPS, but engagement of LPS in turn can induce galectin-3 oligomerization, suggesting that LPS may regulate galectin-3 activity given that galectin-3-mediated biological processes have been attributed to oligomerization (82). LPS-interactions with galectin-3 appear to enhance galectin-3-dependent stimulation of neutrophil oxidative burst, possibly through optimization of galectin-3-mediated clustering of neutrophil counter receptors (83). In contrast, galectin-3 knockout (KO) mice exhibit a heightened pro-inflammatory response and increased mortality rate following endotoxin challenge, suggesting that galectin-3 may attenuate immune responses to LPS (84). Consistent with this, galectin-3 KO mice are resistant to infection with Salmonella BRD509, possibly reflecting an increased inflammatory response that is signified by higher nitrite and $\mathrm{H}_{2} \mathrm{O}_{2}$ levels following exposure (84). As this study utilized several different types of LPS, including Escherichia coli O111:B4 and Salmonella minnesota Re 595, distinct outcomes observed following galectin-3-LPS interactions may reflect differences in galectin-3 binding toward different forms of LPS. In this manner, it is intriguing to speculate that perhaps the presence, absence and even type of LPS may serve as a rheostat that uniquely modulates galectin-mediated activation of neutrophils and perhaps other immune cells following microbial exposure.

Although the fine specificity of galectin interactions with LPS remains to be defined, recent studies suggest that very distinct interactions with specific galectins can occur as a result of unique $O$-antigen determinants on the surface of microbes. While the core carbohydrate structures and lipid A moiety of LPS can often be shared between different strains of microbes, $O$-antigens are synthesized by a distinct set of glycosyltransferases that are often unique to individual strains of microbes $(85,86)$. Differences in seroreactivity toward distinct carbohydrate $O$-antigens have been used for decades to define individual strains within microbial species. These $O$-antigens often incorporate a wide variety of unique monosaccharide structures not found in mammals, which directly contributes to the antigenic diversification observed on the surface of microbes (9). Recent studies suggest that several galectin family members, including galectin- 4 and galectin- 8 , possess the ability to preferentially recognize $O$-antigens that possess common features of mammalian glycans $(87,88)$. As $O$-antigens completely envelope a microbe, decoration with mammalian-like carbohydrates results in a form of molecular mimicry that may serve as a mechanism to avoid adaptive immunity. However, galectins not only appear to possess the ability to recognize microbes that decorate themselves in various forms of molecular mimicry, but engagement of these microbes by galectins often results in microbial death $(87,88)$. In this way, galectins appear to fill an important gap in adaptive immunity toward self-like antigens by directly targeting microbes that utilize molecular mimicry $(89,90)$.

While many studies examined the potential consequences of galectin interactions with LPS, and $O$-antigens in particular, in vitro, the potential outcome of these interactions in vivo remained elusive for many years. Early studies demonstrated that galectins are expressed along various epithelial surfaces, suggesting that these GBPs may be uniquely poised to engage microbes and therefore provide a direct form of innate immunity $(74,79,91)$. Consistent with this possibility, H. pylori exposure results in the upregulation of galectin-3 transcription $(92,93)$. Subsequent studies demonstrated that $H$. pylori exposure not only results in galectin-3 transcriptional activation, but also directly induces galectin-3 expression and secretion $(81,94) . H$. pylori exposure in turn results in galectin-3 engagement of $H$. pylori, which reduces $H$. pyloriepithelial interactions and directly induces microbial death (95). Moreover, exposure of galectin-3 KO mice to $H$. pylori results in significantly enhanced $H$. pylori penetration into the gastric glands, higher bacterial load, and reduced ability of macrophages to kill these microbes (96). Consistent with the specificity of this interaction for $H$. pylori $O$-antigens, Escherichia coli strains which presumably do not express $O$-antigens recognized by galectins fail to experience any difference in macrophage-dependent eradication between WT and galectin-3 KO mice (96). Similarly, inclusion of thiodigalactoside, a non-metabolisable inhibitor of galectins results in the outgrowth of microbes in vivo that are sensitive to galectinmediated killing in vitro, while failing to alter the viability of related microbes that are resistant to galectin-induced death (87). Intriguingly, while the above studies point to a bactericidal role for galectins in vivo, emerging studies indicate that some microbes may have also evolved the ability to utilize galectins to actually facilitate infection. In this context, galectins may bind microbes but fail to kill, thus facilitating host attachment and subsequent infection. This is one possible explanation for the paradox that was observed with galectin-3 and $N$. meningitides, where galectin-3 can bind $N$. meningitides, yet galectin-3 $\mathrm{KO}$ mice actually experience significantly reduced colony forming units (CFUs) following exposure to $N$. meningitides (80).

Several studies suggest that the ability of galectins to bind potential microbial pathogens may reflect an early evolutionary development that predates adaptive immunity. For example, ex- 
posure of the kuruma shrimp (Marsupenaeus japonicus) to Vibrio anguillarum results in significant galectin upregulation, which appears to not only facilitate microbial engagement, but also clearance (97). Similarly, the amphioxus Branchiostoma belcheri tsingtauense galectin, BbtGal, is expressed in a variety of immune related organs, strongly suggesting a potential role for this galectin in immune defense. Indeed, BbtGal binds Vibrio vulnificus, suggesting a potential role in the immune recognition and potential clearance of this pathogen. Although the exact binding determinants required for this interaction remain unknown, BbtGal did not recognize V. parahaemolyticus or Staphylococcus aureus, suggesting that similar to some mammalian galectins, BbtGal exhibits some microbial specificity (98). In contrast to mediating microbial recognition, a recent study in Caenorhabditis elegans suggests that galectins may impact the consequence of pathogen exposure through a less direct mechanism. Bacillus thuringiensis mediates C. elegans pathogenesis in part through Cry5B, a toxin with carbohydrate binding activity toward cell surface $C$. elegans glycolipids (15). Exposure of C. elegans to E. coli expressing Cry5B results in significant upregulation of the C. elegans galectin, LEC-8, which instead of engaging $B$. thuringiensis directly, appears to compete with Cry5B binding at the cell surface, thereby reducing the probability of Cry5B-mediated pathogenesis. Consistent with this, genetic deletion of LEC-8 results in enhanced C. elegans susceptibility to Cry5B (15).

Similar to C. elegans, a recent study demonstrated that galectins might similarly use less direct methods of microbial protection to influence the consequences of host interactions with microbes within a host cell. Galectins are synthesized on free ribosomes, without a secretory motif, where they accumulate in the cytosol of the cell, compartmentalized away from endogenous carbohydrate ligands that are expressed in the lumens of the ER and Golgi apparatus. As a result, galectin synthesis results in the accumulation of a GBP within the cell without the presence of its cognate carbohydrate ligand. Recent data demonstrate that following Salmonella infection, vesicular damage results in cytosolic exposure of endocytosed mammalian cell surface glycans, resulting in exposure of galectin- 8 ligands. In this setting, galectin- 8 binding results in the recruitment of NDP52, which leads to autophagocytic events that restrict Salmonella growth (99). While current data suggest that galectin participation in the restriction of Salmonella growth may be fairly specific to galectin-8 (99), future studies will likely determine whether other galectins trigger analogous events that alert the cell of impending infection or likewise directly contribute to microbial death. Indeed, earlier studies suggested that interactions between galectin-3 and mycobacterium mycolic acid may serve as a similar receptor system to alert cells and thereby facilitate subsequent mycobacteria removal (100), while recent data suggest that galectin-3 may direct antimicrobial cargo to the appropriate cellular vacuoles (101).

\section{E. Galectin Interactions with Viruses}

In parallel with early studies describing potential interactions between galectin-3 and bacterial LPS, several studies began examining the potential impact of galectins on viral infection (Fig. 3). Early data demonstrated that expression of the HIV Tat protein results in enhanced galectin-3 production (102). As viruses invade host cells, virion production often results in the incorporation of host glycan signatures that would also be predicted to serve as ligands for galectins. Consistent with this, subsequent studies not only suggested that HIV infection could regulate galectin expres-

\section{Galectin-3}

\section{$\uparrow$ HSV infection}

\section{Galectin-1 \\ ^ HIV GP120 interactions with CD4 \\ A HIV infection \\ $\uparrow$ HTLV infection \\ $\checkmark$ Nipah virus fusion \\ $\downarrow$ Nipah virus-induced syncytia formation \\ $\downarrow$ Influenza virus hemagglutination/attachment $\downarrow$ Hendra virus infection}

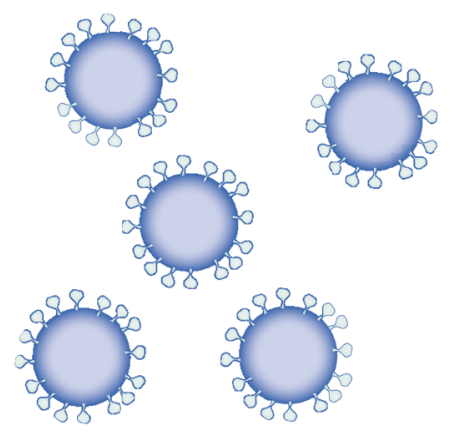

Galectin-9

$\uparrow$ Protein disulfide isomerase stability $\uparrow$ HIV infection

$\uparrow$ HIV reactivation

$\downarrow$ HIV receptor expression

Fig. 3. Galectin interactions with viruses. Different galectin family members recognize a variety of viruses with distinct outcomes. While viruses such as human immunodeficiency virus (HIV) can utilize galectins to gain entry into a cell, galectins appear to also inhibit the development and consequences of infection following interactions with other viruses. Red arrows indicate that the activity is increased by the respective galectin, while blue arrows represent an activity that the indicated galectin decreases. 
sion, but that galectin itself may facilitate viral entry. Galectin-1 possesses the ability to specifically engage CD4 glycans and the glycan determinants of GP120, thereby enhancing the interactions between HIV virions and CD4 ${ }^{+}$target cells (103). Moreover, addition of recombinant galectin-1 enhances the ability of HIV to infect both monocyte-derived macrophages and PHA-activated PBMCs (104). Consistent with this, factors that upregulate galectin-1 have been shown to alter monocyte-derived macrophage sensitivity to HIV infection (105). Galectin-1-mediated enhancement of HIV infection did not seem to reflect a general property of galectin family members, as incubation with galectin-3 did not enhance infection when evaluated in parallel (104). Galectin-1-mediated augmentation of HIV infection occurs independent of HIV fusion events, as fusion inhibitors fail to alter the impact of galectin-1 on HIV viral infection (104). Galectin-1 engagement of GP120 occurs through $\mathrm{N}$-glycans, with similar interactions likewise mediating galectin-1 binding to CD4. Thus, galectin-1 appears to crosslink CD4-GP120 complexes through specific $N$-glycan interactions. As with the inability of galectin-3 to facilitate HIV infection, galectin-3 also failed to recognize GP120 N-glycans when evaluated in parallel (106). These results not only provide unique insight into regulators of HIV infection, but also suggest novel avenues aimed at reducing HIV infections through prevention of galectin-1-mediated events $(107,108)$. The ability of galectin-1 to enhance viral infection does not appear to be limited to HIV as galectin-1 similarly enhances adhesion and subsequent infection by human T-cell lymphotropic virus 1 (HTLV-1) (109).

Galectin-mediated enhancement of HIV infection is not limited to galectin-1. Galectin-9 appears to also impact HIV infection, albeit through a less direct mechanism. Galectin-9 enhances HIV infection through stabilization of protein disulfide isomerase at the cell surface, which alters cell surface redox potential, resulting in alterations in $\mathrm{T}$ cell function that increase cellular sensitivity to HIV infection (110). In patients, galectin-9 levels become significantly elevated during acute HIV infection, but drop following initiation of antiretroviral treatment (111). However, whether serum galectin- 9 detected in these assays reflects active protein remains to be determined. Galectin-9 may also alter HIV infection outcomes by engaging infected cells and reversing HIV latency, resulting in significant increases in HIV transcription. This effect appears to be fairly specific to galectin-9, as incubation of HIVinfected cells with galectins-1, 3, 4, 7 or 8 fails to similarly impact HIV reactivation. However, HIV virions produced by galectin9-stimulated cells exhibit a reduced ability to induce subsequent infection (112), suggesting that galectin-9-induced reactivation comes at a fitness cost of unknown mechanism. In contrast, some studies showed that galectin- 9 engagement of $\mathrm{CD}^{+} \mathrm{T}$ cells may result in downregulation of HIV co-receptors CCR5 and CXCR4 on the $\mathrm{T}$ cell surface, suggesting that, in some settings, galectin- 9 may actually reduce cellular sensitivity to HIV infection (113).

Although early studies failed to detect specific interactions between HIV and galectin-3, levels of galectin-3 binding protein are positively associated with HIV transmission from breast milk (114), suggesting a potential role for galectin-3 in HIV pathogenesis. Additional studies demonstrate that while galectin-3 does not appear to impact HIV adhesion and initial infection, galectin-3 may promote viral budding by facilitating associations between Alix and Gag (115). Collaborative interactions between fibronectin and galectin-3 also appear to facilitate transcellular infection by enhancing the fusion of exosomes derived from HIV-infected DCs to T cells (116). Thus, HIV appears to have co-opted multiple galectin family members to facilitate HIV infection through a variety of distinct mechanisms. While galectin-3 may not directly engage $\mathrm{HIV}$, it does possess the ability to recognize and engage other viruses. Galectin-3 interacts with HSV-1 and this binding appears to directly enhance HSV-1 infection, as knockdown of galectin-3 inhibits the ability of HSV-1 to infect cultured human corneal keratinocytes. However, evolution appears to have selected for a counter measure to reduce or prevent galectin-3-mediated HSV-1 infection. Secreted mucins inhibit HSV-1 infection, likely through competitive interactions with galectin-3 that prevent the binding of galectin-3 to HSV-1, thereby reducing the ability of HSV-1 to utilize galectin-3 for host engagement and subsequent infection (117).

In contrast to the various ways through which HIV utilizes galectin family members to enhance infection, galectin-1 can inhibit Nipah virus fusion. This inhibition by galectin-1 is not limited to Nipah virus, as several paramyxoviridae family members, including Hendra virus and human parainfluenza virus type III are also sensitive to galectin-1-mediated inhibition of viral fusion. However, the ability of galectin-1 to inhibit potential infection by these viruses does not appear to reflect a general antiviral galectin-1 activity, as the addition of exogenous galectin-1 failed to similarly reduce fusion of human T lymphotropic virus II (HTLV II), murine leukemia virus (MLV) or vaccinia (WR strain) (118). Similar to the glycan recognition requirements that permit galectin-1 enhancement of HIV infection, the ability of galectin-1 to inhibit Nipah virus fusion requires recognition of viral $N$-glycans. Differences in the outcome of galectin-1 engagement of Nipah versus HIV may in part reflect the ability of galectin-1 to induce aberrant oligomerization of Nipah glycoproteins (118), which in turn appears to impact engagement of the host cell surface. Importantly, the timing of galectin-1 exposure may be important in dictating the outcome of galectin-1 on Nipah virus infection. Early exposure to galectin-1 may actually enhance infection by initially bridging Nipah virus 
to the endothelial cell surface, whereas exposure of Nipah virusinfected endothelial cells to exogenous galectin-1 following viral penetration and replication inhibits endothelial syncytial formation (118).

Galectin-1 also appears to impact influenza infection. Not only does influenza infection result in enhanced galectin-1 secretion into the bronchial alveolar fluid, but overexpression of galectin-1 also suppresses influenza viral replication. Moreover, galectin-1 directly interacts with influenza, blocking the ability of the virus to induce hemagglutination and therefore potentially impacting viral attachment. Consistent with this, intranasal delivery of recombinant galectin-1 reduces viral titers following influenza challenge, while galectin-1 KO mice experience higher viral loads when compared to controls (119). Galectin-1 may not only impact the outcome of influenza exposure, but may also alter the likelihood of bacterial superinfection following influenza infection. Influenza-induced desialylation of air epithelial cells exposes terminal Gal $\beta 1-4$ GlcNAc (LacNAc) structures, which serve as common sites of galectin attachment. As Streptococcus pneumoniae engages epithelial cells through interactions with galectin-1 and galectin-3 (120), enhanced exposure of galectin ligands following influenza infection not only increases cell surface binding by galectins, but also appears to increase $S$. pneumoniae colonization and risk for infection, providing one mechanism whereby influenza infection may predispose individuals to bacterial superinfection (120). However, galectin engagement of $S$. pneumoniae may not be entirely beneficial for $S$. pneumoniae as data suggest that galectin-3 can fa- cilitate neutrophil phagocytosis and also exert some bacteriostatic activity toward S. pneumoniae (121).

Importantly, the ability of galectins to inhibit viral infection may not be limited to mammals. Galectins from Zebra fish (Danio rerio), including the prototype galectin-1 (DRgal1-L2) and chimeric galectin-3 (DRgal3-L1), possess the ability to bind infectious hematopoietic necrosis virus (IHNV). Galectin engagement of IHNV, which is a Rhabdovirdidae that infects teleost fish (such as salmon and trout), prevents its ability to induce infection $(122,123)$.

\section{F. Galectin Interactions with Protozoa, Trematodes and Nematodes}

Early studies examining the potential role of galectins in regulating host-parasite interactions focused on the ability of galectin-3 to potentiate parasite engagement of host (Fig. 4). These studies demonstrated that galectin-3 not only possesses the capacity to bind Trypanosoma cruzi, but also facilitates T. cruzi's interaction with a component of the extracellular matrix, laminin (75). Subsequent studies extended these initial findings, demonstrating that galectin-3 independently binds aortic smooth muscle cells and $T$. cruzi, directly enhancing T. cruzi adhesion to aortic smooth muscle cells (124). Importantly, galectin-3-mediated adhesion was not only observed following the addition of exogenous recombinant galectin-3, but knockdown of galectin-3 also reduced T. cruzi adhesion, strongly suggesting the endogenous galectin-3 is capable of facilitating $T$. cruzi interactions with host (124). These results suggest that galectin-3 may not only enhance T. cruzi infection, but

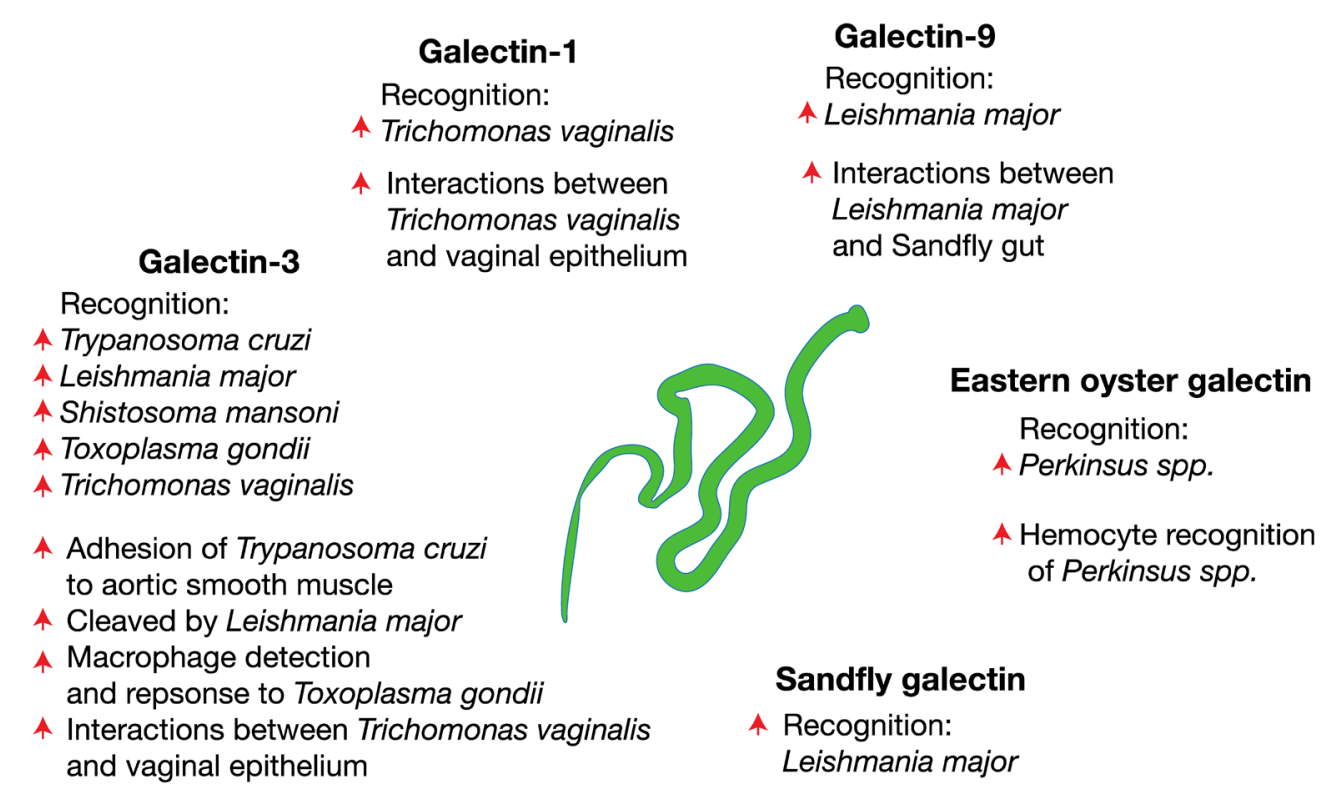

Fig. 4. Galectin interactions with protozoa, trematodes and nematodes. Different galectin family members recognize protozoa, trematodes and nematodes. Galectin interactions with some parasites facilitate immune detection and subsequent activation, while other parasites appear to use galectins as a source of host attachment and infection. Red arrows indicate that the activity is increased by the respective galectin. 
may also contribute to the pathogenesis underlying the significant cardiovascular complications often exemplified in $T$. cruzi-driven Chagas disease. While the exact glycan determinants that mediate interactions between galectin-3 and T. cruzi remain to be elucidated, examination of potential T. cruzi-galectin-3 binding partners demonstrated that multiple $T$. cruzi glycoproteins express potential galectin-3 ligands (75). In contrast, recent data suggest that galectin-1 may actually inhibit $T$. cruzi infection of cardiac cells (125).

Subsequent studies demonstrated that galectin-3 engagement of parasites is not limited to T. cruzi. Galectin-3 also displays significant binding toward the lipophosphoglycans (LPGs) of Leishmania major (19). Importantly, galectin-3 failed to similarly recognize LPGs harvested from Leishmania donovani (19), suggesting some specificity to this interaction. Unlike the putative role of galectin-3 in facilitating host interactions with T. cruzi, galectin-3 fails to facilitate direct $L$. major binding to macrophages (126). However, galectin-3-mediated regulation of macrophage function may be important in eliminating L. major following exposure (126). Intriguingly, L. major appears to have evolved the ability to regulate this process, as $L$. major proteolytically cleaves galectin-3, thereby potentially reducing or even eliminating the ability of galectin-3 to facilitate a productive immune response following L. major exposure (19). Galectin interactions with L. major are not limited to galectin-3, as subsequent studies demonstrated that galectin-9 also possesses the ability to recognize L. major promastigotes, while similarly failing to recognize $L$. donovani (126).

Galectin-3 also recognizes the soluble egg antigens of Schistosoma mansoni, likely through GalNAc $\beta 1-4$ GlcNAc (LacdiNAc) glycan interactions. These observations provided some of the first details regarding the actual carbohydrate determinants recognized by galectins on a parasite surface (127). Consistent with the potential importance of this interaction in vivo, significant galectin-3 co-localizes with LacdiNAc and S. mansoni in the livers of infected hamsters (127). Subsequent studies demonstrated that while the number, localization and overall turnover of $\mathrm{T}$ cell, $\mathrm{B}$ cell and macrophage populations, in addition to the humoral immune response and the size of granuloma formation, may differ in galectin-3 KO mice when compared with WT mice following $S$. mansoni infection $(128,129)$, no difference in the worm burden or overall numbers of eggs in the liver or intestine could be detected in galectin-3 KO versus WT controls (128). As a result, future studies will be needed to define the consequences of galectin-3-S. mansoni interactions in vivo on overall immune activation and polarization.

Similar to interactions between galectin-3 and LPS, data suggest that galectin-3 may employ analogous modes of binding toward Toxoplasma gondii glycosylphosphatidylinositols (GPIs). While galectin-3 interactions with GPIs isolated from $T$. gondii could be inhibited by lactose and appeared to be high affinity (reaching $7 \mathrm{nM} K_{\mathrm{d}}$ ), galectin-3 also displayed significant interactions with both the glycan moiety and diacylglycerol as measured by surface plasmon resonance. Galectin-3 interactions with GPIs of $T$. gondii may facilitate immune detection and response, as galectin-3 deletion reduced TNF $\alpha$ production by macrophages following exposure to T. gondii GPIs (130). Furthermore, the role of galectin-3 in facilitating immune responsiveness to $T$. gondii appears to be somewhat specific, as galectin-1 KO mice failed to display a similar difference in TNF $\alpha$ production following $T$. gondii GPI exposure (130). Similar to challenge with S. mansoni, subsequent studies demonstrated altered inflammatory response following exposure in some organs, such as the liver and intestine, following challenge of galectin-3 KO with no differences in the parasite burden. In contrast, a reduced number of inflammatory cells and increased parasite burden occurred in the brain of galectin-3 KO mice. Interestingly, the route of $T$. gondii exposure impacted overall mortality, with galectin-3 KO recipients displaying a higher mortality following intraperitoneal injection, but no observable difference following oral exposure (72). Haemonchus contortus or Fasciola hepatica exposure also results in the upregulation of sheep galectin $(131,132)$, which may regulate and/ or serve as an effector molecule for eosinophil responses observed following exposure $(133,134)$.

The ability of galectins to engage parasites and potentially regulate subsequent immune activity appears to be fairly conserved. Activation of hemocytes from the eastern oyster (Crassostrea virginica) results in significant secretion $C$. virginica galectin (cvgal-1). While cvgal-1 appears to possess the ability to recognize a wide variety of microbes, it exhibits distinct binding to Perkinsus marinus (135). This interaction may facilitate hemocyte engagement of $P$. marinus, as galectins also bind hemocyte glycans, in part through recognition of blood group A glycan determinants (136). Like many species, $C$. virginica expresses more than one galectin. A second galectin, cvgal-2, exhibits relatively broad expression in $C$. virginica tissues and similar to cvgal-1, recognizes blood group antigens and facilitates attachment of Perkinsus parasites to hemocytes (137).

Galectin-1 may also regulate the outcome of host interactions with Trichomonas vaginalis. Early data demonstrated that galectin-1 can impact $T$. vaginalis adherence to vaginal epithelium (138). The role of galectin-1 in T. vaginalis vaginal adhesion displays some specificity, as galectin-7 failed to similarly impact adhesion to cervical or vaginal epithelial cells (139). The ability of galectin-1 to mediate $T$. vaginalis adhesion was not limited to the addition of the exogenous protein, as knockdown of galectin-1 inhibited adhesion events, strongly suggesting that the endogenous 
protein is capable of mediating this interaction (139). Subsequent studies demonstrated that $T$. vaginalis adhesion to cervical epithelial cells might not be limited to galectin-1, but that galectin-3 may also participate in these interactions. Galectin-1 and galectin- 3 binding to $T$. vaginalis may occur through engagement of lipophosphoglycans and ceramide phosphoinositol glycan cores, as galectin-1 and galectin-3 bound these T. vaginalis structures (140). Engagement of these structures may not only facilitate $T$. vaginalis adhesion and therefore infection, but it is also thought that these ligands may serve as decoy receptors that reduce galectin engagement of host immune cell glycans, thereby reducing galectinmediated activation of immunologic responses required for efficient $T$. vaginalis elimination (140). Distinct strains of $T$. vaginalis can differentially engage unique galectin family members in this way (140), thereby eliciting distinct immune responses to $T$. vaginalis in a strain specific manner.

The ability to utilize galectins to facilitate infection is not limited to T. vaginalis. L. major develops from noninfectious promastigotes to infective promastigotes in the midgut of the sandfly Phlebotomus papatasi (141). This critical developmental process requires $L$. major attachment to the sandfly midgut. Early studies demonstrated that the sandfly galectin, PpGalec, is a key component of this attachment phase; blocking PpGalec significantly reduces parasite survival and therefore would be predicted to impact transmission (141). As Anopheles stephensi (mosquito), Rhodnius prolixus (reduviid bug), Ornithodoros moubata (argasid tick) and Biomphalaria glabrata (freshwater snail) all express galectins (142-145), galectins may have a more general role in facilitating parasite lifecycles and potential transmission within a variety of intermediate hosts. In contrast, several parasites appear to express their own galectins, which likewise may facilitate host attachment and eventual infection (146-148).

\section{G. Galectin Interactions with Fungi}

While a number of studies have examined potential interactions between galectins and a variety of different microbes, less is known about the role of galectins in directly detecting and regulating interactions with fungal organisms (Fig. 5). The earliest study examining potential galectin interactions with fungal organisms used classic biochemical isolation procedures to define the macrophage receptor responsible for the binding of Candida albicans $\alpha$ 1-2 linked oligomannans (149). This study identified galectin-3 as a $C$. albicans receptor on the macrophage surface (149). Subsequent studies confirmed that galectin-3 not only recognizes Candida albicans, but also fails to recognize Saccharomyces cerevisiae. Despite the lack of canonical Gal $\beta 1-3 / 4-\mathrm{R}$ glycan motifs, lactose completely inhibits galectin-3 interactions with $C$.

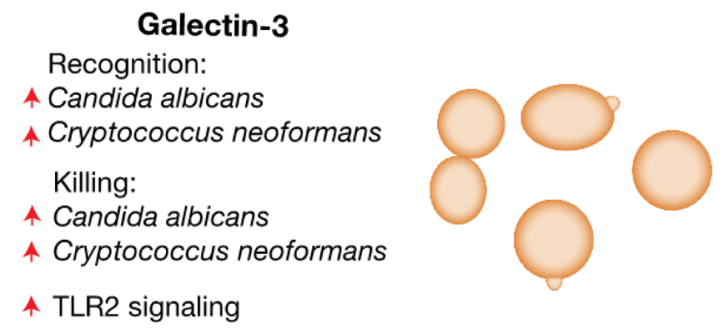

Fig. 5. Galectin interactions with fungi. Galectin-3 recognizes several fungal organisms. Galectin-3 binds Candida albicans and Cryptococcus neoformans and these interactions can result in decreased viability. Galectin-3 engagement may also facilitate immune activation following Candida albicans or Cryptococcus neoformans exposure. Red arrows indicate that the activity is increased by galectin- 3 .

albicans, strongly suggesting that galectin-3-C. albicans interactions are carbohydrate dependent. Consistent with the possibility that galectin-3 may recognize completely distinct glycans on the $C$. albicans surface, $\beta$ 1-2 linked oligomannans also inhibit galectin3-C. albicans interactions $(149,150)$. While the molecular details of this interaction remain to be elucidated, these results suggest a completely distinct type of galectin-glycan binding event. These binding interactions appear to be somewhat specific to galectin-3, as galectin-1 did not engage $C$. albicans. Engagement by galectin-3 resulted in a modest inhibition of $C$. albicans viability, suggesting that one purpose for galectin-3 engagement may in part be to directly kill C. albicans following exposure. Similar to binding, the ability of galectin-3 to reduce $C$. albicans viability appeared to require expression of $\beta 1-2$ oligomannoside expression on the yeast cell surface (150). Subsequent studies demonstrated that galectin-3 not only facilitates direct microbial killing, but also cooperates with TLR2 signaling to enhance macrophage pro-inflammatory cytokine secretion following C. albicans exposure (151). Consistent with this, galectin-3 $\mathrm{KO}$ mice experience reduced transcriptional activation of TLR2, TNF $\alpha$ and IL $1 \beta$ following $C$. albicans exposure in DSS challenged mice (152).

Galectin-3 also directly engages Cryptococcus neoformans and reduces $C$. neoformans growth, possibly through disruption of extracellular vesicles (153). Intratracheal delivery of $C$. neoformans results in upregulation of galectin-3 in the lungs, spleen, serum and brain, with similar increases in galectin-3 expression noted in both immunocompetent and HIV positive individuals following $C$. neoformans infection, strongly suggesting an immune interaction between galectin-3 and C. neoformans exists in vivo (153). Indeed, galectin-3 KO mice experience increased $C$. neoformans burden and mortality following infection. Galectin-3 KO mice also displayed significant changes in key proinflammatory cytokines, including downregulation of IL-6, IL-12 and TNF $\alpha$. As a result, the reduced ability of galectin-3 KO mice 
to clear C. neoformans may reflect both direct galectin-3-mediated effects on $C$. neoformans viability and the ability of galectin-3 to induce an optimal pro-inflammatory immune program following $C$. neoformans challenge (153).

\section{H. Conclusions}

Given the ability of galectins to regulate a wide variety of processes, including the activation state and overall turnover of many different immune cells, it can be difficult to separate the potential role of galectins in directly binding and potentially killing microbes from the effects galectins may have on immune function in general (154). However, as galectins are expressed in all metazoans, including evolutionary ancient organisms such as the tunicate Didemnum candidum $(155,156)$, their ability to recognize and respond to microbial challenge likely represents one of their earliest biological functions $(16,157-160)$. Despite the apparent specificity of galectins for bacterial glycans with mammalian-like features $(48,87,88)$, galectin-mediated interactions with many microbes do not appear to require the presence of mammalian-like structures $(16,157-160)$, suggesting that early galectin-mediated immunity may have possessed an even broader form of microbial recognition. This may reflect a lack of adaptive immunity in these organisms and therefore a greater reliance on relatively broad binding characteristics of innate immune factors, as occurs for other innate immune lectins involved in host immunity (161). As microbes evolved the ability to diversify their glycan repertoire, these unique structures likely outstripped the ability of galectins and possibly other innate immune factors to adequately recognize them, possibly setting the stage for the evolution of adaptive immunity. However, very little is actually known about the fine specificity of galectin interactions with many microbes, including the specific glycan determinants required for binding. Given the ability of galectins to recognize the glycan determinants of T. cruzi, L. major, C. albicans and C. neoformans in addition to many other bacteria and viruses, the breadth of glycans recognized by mammalian galectins may be much different than originally anticipated. Additional studies will be needed to characterize the overall specificity of galectin family members for microbial glycans. The ability of galectins to not only recognize microbes, but also regulate immune function, in addition to a wide variety of other biological processes through both carbohydrate-dependent and independent mechanisms, makes the galectin family one of the most pleiotropic protein families described. As this diversity of function can make the study of galectins challenging, future studies will need to use a variety of approaches and model organisms to dissect the role of individual galectin family members in directly regulating host interactions with microbes.

\section{References}

1. Yano, J. M., Yu, K., Donaldson, G. P., Shastri, G. G., Ann, P., Ma, L., Nagler, C. R., Ismagilov, R. F., Mazmanian, S. K., and Hsiao, E. Y. (2015) Cell 161, 264-276.

2. Wu, H. J., and Wu, E. (2012) Gut Microbes 3, 4-14.

3. Honda, K., and Littman, D. R. (2016) Nature 535, 75-84.

4. Stecher, B., and Hardt, W. D. (2008) Trends Microbiol. 16, 107-114.

5. Sato, S., St-Pierre, C., Bhaumik, P., and Nieminen, J. (2009) Immunol. Rev. 230, 172-187.

6. van Kooyk, Y., and Rabinovich, G. A. (2008) Nat. Immunol. 9, 593-601.

7. Rabinovich, G. A., and Toscano, M. A. (2009) Nat. Rev. Immunol. 9, 338-352.

8. Ni, Y., and Tizard, I. (1996) Vet. Immunol. Immunopathol. 55, 205-223.

9. Wesener, D. A., Wangkanont, K., McBride, R., Song, X., Kraft, M. B., Hodges, H. L., Zarling, L. C., Splain, R. A., Smith, D. F., Cummings, R. D., Paulson, J. C., Forest, K. T., and Kiessling, L. L. (2015) Nat. Struct. Mol. Biol. 22, 603-610.

10. Varki, A., Cummings, R., Esko, J., et al. (2009) Essentials of Glycobiology, 2nd Ed., Cold Spring Harbor Laboratory Press.

11. Grewal, P. K., Uchiyama, S., Ditto, D., Varki, N., Le, D. T., Nizet, V., and Marth, J. D. (2008) Nat. Med. 14, $648-655$.

12. Marth, J. D., and Grewal, P. K. (2008) Nat. Rev. Immunol. 8, 874-887.

13. Cummings, R. D. (2009) Mol. Biosyst. 5, 1087-1104.

14. van Die, I., and Cummings, R. D. (2017) Front. Immunol. 8, 1677.

15. Ideo, H., Fukushima, K., Gengyo-Ando, K., Mitani, S., Dejima, K., Nomura, K., and Yamashita, K. (2009) J. Biol. Chem. $284,26493-26501$.

16. Sato, S., and Nieminen, J. (2004) Glycoconj. J. 19, 583-591.

17. Vasta, G. R. (2009) Nat. Rev. Microbiol. 7, 424-438.

18. Griffitts, J. S., Haslam, S. M., Yang, T., Garczynski, S. F., Mulloy, B., Morris, H., Cremer, P. S., Dell, A., Adang, M. J., and Aroian, R. V. (2005) Science 307, 922-925.

19. Pelletier, I., and Sato, S. (2002) J. Biol. Chem. 277, 17663-17670.

20. Morell, A. G., Irvine, R. A., Sternlieb, I., Scheinberg, I. H., and Ashwell, G. (1968) J. Biol. Chem. 243, 155-159.

21. Morell, A. G., Gregoriadis, G., Scheinberg, I. H., Hickman, J., and Ashwell, G. (1971) J. Biol. Chem. 246, $1461-1467$.

22. Van Den Hamer, C. J., Morell, A. G., Scheinberg, I. H., Hickman, J., and Ashwell, G. (1970) J. Biol. Chem. $245,4397-4402$.

23. Teichberg, V. I., Silman, I., Beitsch, D. D., and Resheff, G. (1975) Proc. Natl. Acad. Sci. U.S.A. 72, 1383-1387.

24. Nowak, T. P., Haywood, P. L., and Barondes, S. H. (1976) Biochem. Biophys. Res. Commun. 68, 650-657. 
25. de Waard, A., Hickman, S., and Kornfeld, S. (1976) J. Biol. Chem. 251, 7581-7587.

26. Leffler, H., Carlsson, S., Hedlund, M., Qian, Y., and Poirier, F. (2004) Glycoconj. J. 19, 433-440.

27. Levi, G., and Teichberg, V. I. (1981) J. Biol. Chem. 256, 5735-5740.

28. Hirabayashi, J., Hashidate, T., Arata, Y., Nishi, N., Nakamura, T., Hirashima, M., Urashima, T., Oka, T., Futai, M., Muller, W. E., Yagi, F., and Kasai, K. (2002) Biochim. Biophys. Acta 1572, 232-254.

29. Dam, T. K., Gabius, H. J., Andre, S., Kaltner, H., Lensch, M., and Brewer, C. F. (2005) Biochemistry 44, 12564-12571.

30. Sorme, P., Kahl-Knutsson, B., Huflejt, M., Nilsson, U. J., and Leffler, H. (2004) Anal. Biochem. 334, 36-47.

31. Levi, G., and Teichberg, V. I. (1982) FEBS Lett. 148, 145-148.

32. Levi, G., and Teichberg, V. I. (1985) Biochem. J. 226, 379-384.

33. Leffler, H., and Barondes, S. H. (1986) J. Biol. Chem. 261, 10119-10126.

34. Laing, J. G., Robertson, M. W., Gritzmacher, C. A., Wang, J. L., and Liu, F. T. (1989) J. Biol. Chem. 264, 1097-1010.

35. Lobsanov, Y. D., Gitt, M. A., Leffler, H., Barondes, S. H., and Rini, J. M. (1993) J. Biol. Chem. 268, 27034-27038.

36. Whitney, P. L., Powell, J. T., and Sanford, G. L. (1986) Biochem. J. 238, 683-689.

37. Pande, A. H., Gupta, R. K., Sumati, and Hajela, K. (2003) Protein Pept. Lett. 10, 265-275.

38. Clerch, L. B., Whitney, P., Hass, M., Brew, K., Miller, T., Werner, R., and Massaro, D. (1988) Biochemistry 27, $692-699$.

39. Stowell, S. R., Cho, M., Feasley, C. L., Arthur, C. M., Song, X., Colucci, J. K., Karmakar, S., Mehta, P., Dias-Baruffi, M., McEver, R. P., and Cummings, R. D. (2009) J. Biol. Chem. 284, 4989-4999.

40. Sakakura, M., Tamura, M., Fujii, N., Takeuchi, T., Hatanaka, T., Kishimoto, S., Arata, Y., and Takahashi, H. (2018) FEBS J. 285, $1129-1145$.

41. Tamura, M., Sasai, A., Ozawa, R., Saito, M., Yamamoto, K., Takeuchi, T., Ohtake, K., Tateno, H., Hirabayashi, J., Kobayashi, J., and Arata, Y. (2016) J. Biochem. 160, 233-241.

42. Tracey, B. M., Feizi, T., Abbott, W. M., Carruthers, R. A., Green, B. N., and Lawson, A. M. (1992) J. Biol. Chem. 267, $10342-10347$.

43. Hirabayashi, J., and Kasai, K. (1991) J. Biol. Chem. 266, 23648-23653.

44. Cho, M., and Cummings, R. D. (1995) J. Biol. Chem. 270, 5198-5206.

45. Merkle, R. K., and Cummings, R. D. (1988) J. Biol. Chem. 263, 16143-16149.

46. Brewer, C. F. (2004) Glycoconj. J. 19, 459-465.

47. Barondes, S. H., Castronovo, V., Cooper, D. N. W., Cummings, R. D., Drickamer, K., Felzi, T., Gitt, M. A., Hirabayashi, J., Hughes, C., Kasai, K., Leffler, H., Liu, F.-T., Lotan, R., Mercurio, A. M., Monsigny, M., Pillai, S., Poirer, F., Raz, A., Rigby, P. W. J., Rini, J. M., and Wang, J. L. (1994) Cell 76, 597-598.

48. Stowell, S. R., Arthur, C. M., Mehta, P., Slanina, K. A., Blixt, O., Leffler, H., Smith, D. F., and Cummings, R. D. (2008) J. Biol. Chem. 283, 10109-10123.

49. Lepur, A., Salomonsson, E., Nilsson, U. J., and Leffler, H. (2012) J. Biol. Chem. 287, 21751-21756.

50. Stowell, S. R., Arthur, C. M., Slanina, K. A., Horton, J. R., Smith, D. F., and Cummings, R. D. (2008) J. Biol. Chem. 283, $20547-20559$.

51. Simpson, D. L., Thorne, D. R., and Loh, H. H. (1977) Nature 266, 367-369.

52. Kobiler, D., and Barondes, S. H. (1977) Dev. Biol. 60, 326-330.

53. Kaufman, S. J., and Lawless, M. L. (1980) Differentiation 16, 41-48.

54. Levi, G., Tarrab-Hazdai, R., and Teichberg, V. I. (1983) Eur. J. Immunol. 13, 500-507.

55. Offner, H., Celnik, B., Bringman, T. S., Casentini-Borocz, D., Nedwin, G. E., and Vandenbark, A. A. (1990) J. Neuroimmunol. $28,177-184$.

56. Toscano, M. A., Bianco, G. A., Ilarregui, J. M., Croci, D. O., Correale, J., Hernandez, J. D., Zwirner, N. W., Poirier, F., Riley, E. M., Baum, L. G., and Rabinovich, G. A. (2007) Nat. Immunol. 8, 825-834.

57. Santucci, L., Fiorucci, S., Cammilleri, F., Servillo, G., Federici, B., and Morelli, A. (2000) Hepatology 31, 399-406.

58. Santucci, L., Fiorucci, S., Rubinstein, N., Mencarelli, A., Palazzetti, B., Federici, B., Rabinovich, G. A., and Morelli, A. (2003) Gastroenterology 124, 1381-1394.

59. Tsuchiyama, Y., Wada, J., Zhang, H., Morita, Y., Hiragushi, K., Hida, K., Shikata, K., Yamamura, M., Kanwar, Y. S., and Makino, H. (2000) Kidney Int. 58, 1941-1952.

60. Rabinovich, G. A., Daly, G., Dreja, H., Tailor, H., Riera, C. M., Hirabayashi, J., and Chernajovsky, Y. (1999) J. Exp. Med. $190,385-398$.

61. Blois, S. M., Ilarregui, J. M., Tometten, M., Garcia, M., Orsal, A. S., Cordo-Russo, R., Toscano, M. A., Bianco, G. A., Kobelt, P., Handjiski, B., Tirado, I., Markert, U. R., Klapp, B. F., Poirier, F., Szekeres-Bartho, J., Rabinovich, G. A., and Arck, P. C. (2007) Nat. Med. 13, $1450-1457$.

62. Ilarregui, J. M., Croci, D. O., Bianco, G. A., Toscano, M. A., Salatino, M., Vermeulen, M. E., Geffner, J. R., and Rabinovich, G. A. (2009) Nat. Immunol. 10, 981-991.

63. Rabinovich, G. A., van Kooyk, Y., and Cobb, B. A. (2012) Ann. N. Y. Acad. Sci. 1253, 1-15.

64. Cerliani, J. P., Stowell, S. R., Mascanfroni, I. D., Arthur, C. M., Cummings, R. D., and Rabinovich, G. A. (2011) J. Clin. Immunol. 31, 10-21.

65. Sundblad, V., Morosi, L. G., Geffner, J. R., and Rabinovich, G. A. (2017) J. Immunol. 199, 3721-3730.

66. Wollenberg, A., de la Salle, H., Hanau, D., Liu, F. T., and Bieber, T. (1993) J. Exp. Med. 178, 777-785.

67. Liu, F. T. (1993) Immunol. Today 14, 486-490.

68. Karlsson, A., Follin, P., Leffler, H., and Dahlgren, C. (1998) Blood 91, 3430-3438.

69. Perillo, N. L., Pace, K. E., Seilhamer, J. J., and Baum, L. G. (1995) Nature 378, 736-739.

70. Robinson, N., Pleasance, J., Piedrafita, D., and Meeusen, E. N. (2011) Int. J. Parasitol. 41, 487-493.

71. Oliveira, F. L., Frazao, P., Chammas, R., Hsu, D. K., Liu, F. T., Borojevic, R., Takiya, C. M., and El-Cheikh, M. C. (2007) J. Leukoc. Biol. 82, 300-310.

72. Bernardes, E. S., Silva, N. M., Ruas, L. P., Mineo, J. R., Loyola, A. M., Hsu, D. K., Liu, F. T., Chammas, R., and Roque-Barreira, M. C. (2006) Am. J. Pathol. 168, 1910-1920.

73. Mey, A., Leffler, H., Hmama, Z., Normier, G., and Revillard, J. P. (1996) J. Immunol. 156, 1572-1577. 
74. Gupta, S. K., Masinick, S., Garrett, M., and Hazlett, L. D. (1997) Infect. Immun. 65, 2747-2753.

75. Moody, T. N., Ochieng, J., and Villalta, F. (2000) FEBS Lett. 470, 305-308.

76. Vasta, G. R., Quesenberry, M., Ahmed, H., and O’Leary, N. (1999) Dev. Comp. Immunol. 23, 401-420.

77. Liu, F. T. (2000) Clin. Immunol. 97, 79-88.

78. Mandrell, R. E., Apicella, M. A., Lindstedt, R., and Leffler, H. (1994) Methods Enzymol. 236, 231-254.

79. John, C. M., Jarvis, G. A., Swanson, K. V., Leffler, H., Cooper, M. D., Huflejt, M. E., and Griffiss, J. M. (2002) Cell. Microbiol. 4, $649-662$.

80. Quattroni, P., Li, Y., Lucchesi, D., Lucas, S., Hood, D. W., Herrmann, M., Gabius, H. J., Tang, C. M., and Exley, R. M. (2012) Cell. Microbiol. 14, $1657-1675$.

81. Fowler, M., Thomas, R. J., Atherton, J., Roberts, I. S., and High, N. J. (2006) Cell. Microbiol. 8, 44-54.

82. Brewer, C. F., Miceli, M. C., and Baum, L. G. (2002) Curr. Opin. Struct. Biol. 12, 616-623.

83. Fermino, M. L., Polli, C. D., Toledo, K. A., Liu, F. T., Hsu, D. K., Roque-Barreira, M. C., Pereira-da-Silva, G., Bernardes, E. S., and HalbwachsMecarelli, L. (2011) PLoS One 6, e26004.

84. Li, Y., Komai-Koma, M., Gilchrist, D. S., Hsu, D. K., Liu, F. T., Springall, T., and Xu, D. (2008) J. Immunol. 181, $2781-2789$.

85. Feng, L., Senchenkova, S. N., Yang, J., Shashkov, A. S., Tao, J., Guo, H., Zhao, G., Knirel, Y. A., Reeves, P., and Wang, L. (2004) J. Bacteriol. 186, 383-392.

86. Rocchetta, H. L., Burrows, L. L., and Lam, J. S. (1999) Microbiol. Mol. Biol. Rev. 63, 523-553.

87. Stowell, S. R., Arthur, C. M., Dias-Baruffi, M., Rodrigues, L. C., Gourdine, J. P., Heimburg-Molinaro, J., Ju, T., Molinaro, R. J., Rivera-Marrero, C., Xia, B., Smith, D. F., and Cummings, R. D. (2010) Nat. Med. 16, 295-301.

88. Stowell, S. R., Arthur, C. M., McBride, R., Berger, O., Razi, N., Heimburg-Molinaro, J., Rodrigues, L. C., Gourdine, J. P., Noll, A. J., von Gunten, S., Smith, D. F., Knirel, Y. A., Paulson, J. C., and Cummings, R. D. (2014) Nat. Chem. Biol. 10, 470-476.

89. Arthur, C. M., Cummings, R. D., and Stowell, S. R. (2014) Curr. Opin. Chem. Biol. 18, 55-61.

90. Arthur, C. M., Patel, S. R., Mener, A., Kamili, N. A., Fasano, R. M., Meyer, E., Winkler, A. M., Sola-Visner, M., Josephson, C. D., and Stowell, S. R. (2015) BioEssays 37, 1327-1337.

91. Gitt, M. A., Colnot, C., Poirier, F., Nani, K. J., Barondes, S. H., and Leffler, H. (1998) J. Biol. Chem. 273, 2954-2960.

92. Huff, J. L., Hansen, L. M., and Solnick, J. V. (2004) Infect. Immun. 72, 5216-5226.

93. Lim, J. W., Kim, H., and Kim, K. H. (2003) Int. J. Biochem. Cell Biol. 35, 1284-1296.

94. Subhash, V. V., and Ho, B. (2016) Cell Biol. Toxicol. 32, 23-35.

95. Subhash, V. V., Ling, S. S., and Ho, B. (2016) Microbiology 162, 1360-1366.

96. Park, A. M., Hagiwara, S., Hsu, D. K., Liu, F. T., and Yoshie, O. (2016) Infect. Immun. 84, 1184-1193.

97. Shi, X. Z., Wang, L., Xu, S., Zhang, X. W., Zhao, X. F., Vasta, G. R., and Wang, J. X. (2014) PLoS One 9, e91794.

98. Yu, Y., Yuan, S., Yu, Y., Huang, H., Feng, K., Pan, M., Huang, S., Dong, M., Chen, S., and Xu, A. (2007) Glycobiology 17, 774-783.

99. Thurston, T. L., Wandel, M. P., von Muhlinen, N., Foeglein, A., and Randow, F. (2012) Nature 482, 414-418.

100. Barboni, E., Coade, S., and Fiori, A. (2005) FEBS Lett. 579, 6749-6755.

101. Feeley, E. M., Pilla-Moffett, D. M., Zwack, E. E., Piro, A. S., Finethy, R., Kolb, J. P., Martinez, J., Brodsky, I. E., and Coers, J. (2017) Proc. Natl. Acad. Sci. U.S.A. 114, E1698-E1706.

102. Fogel, S., Guittaut, M., Legrand, A., Monsigny, M., and Hebert, E. (1999) Glycobiology 9, 383-387.

103. Ouellet, M., Mercier, S., Pelletier, I., Bounou, S., Roy, J., Hirabayashi, J., Sato, S., and Tremblay, M. J. (2005) J. Immunol. 174, $4120-4126$.

104. Mercier, S., St-Pierre, C., Pelletier, I., Ouellet, M., Tremblay, M. J., and Sato, S. (2008) Virology 371, 121-129.

105. Reynolds, J. L., Law, W. C., Mahajan, S. D., Aalinkeel, R., Nair, B., Sykes, D. E., Mammen, M. J., Yong, K. T., Hui, R., Prasad, P. N., and Schwartz, S. A. (2012) J. Immunol. 188, 3757-3765.

106. St-Pierre, C., Manya, H., Ouellet, M., Clark, G. F., Endo, T., Tremblay, M. J., and Sato, S. (2011) J. Virol. 85, $11742-11751$.

107. Reynolds, J. L., Law, W. C., Mahajan, S. D., Aalinkeel, R., Nair, B., Sykes, D. E., Yong, K. T., Hui, R., Prasad, P. N., and Schwartz, S. A. (2012) J. Neuroimmune Pharmacol. 7, 673-685.

108. St-Pierre, C., Ouellet, M., Giguere, D., Ohtake, R., Roy, R., Sato, S., and Tremblay, M. J. (2012) Antimicrob. Agents Chemother. 56, 154-162.

109. Gauthier, S., Pelletier, I., Ouellet, M., Vargas, A., Tremblay, M. J., Sato, S., and Barbeau, B. (2008) Retrovirology 5, 105.

110. Bi, S., Hong, P. W., Lee, B., and Baum, L. G. (2011) Proc. Natl. Acad. Sci. U.S.A. 108, 10650-10655.

111. Saitoh, H., Ashino, Y., Chagan-Yasutan, H., Niki, T., Hirashima, M., and Hattori, T. (2012) Tohoku J. Exp. Med. 228, $157-161$.

112. Abdel-Mohsen, M., Chavez, L., Tandon, R., Chew, G. M., Deng, X., Danesh, A., Keating, S., Lanteri, M., Samuels, M. L., Hoh, R., Sacha, J. B., Norris, P. J., Niki, T., Shikuma, C. M., Hirashima, M., Deeks, S. G., Ndhlovu, L. C., and Pillai, S. K. (2016) PLoS Pathog. 12 , e1005677.

113. Elahi, S., Niki, T., Hirashima, M., and Horton, H. (2012) Blood 119, 4192-4204.

114. Chan, C. S., Kim, H. Y., Autran, C., Kim, J. H., Sinkala, M., Kankasa, C., Mwiya, M., Thea, D. M., Aldrovandi, G. M., Kuhn, L., and Bode, L. (2013) Pediatr. Infect. Dis. J. 32, e473-e475.

115. Wang, S. F., Tsao, C. H., Lin, Y. T., Hsu, D. K., Chiang, M. L., Lo, C. H., Chien, F. C., Chen, P., Arthur Chen, Y. M., Chen, H. Y., and Liu, F. T. (2014) Glycobiology 24, 1022-1035.

116. Kulkarni, R., and Prasad, A. (2017) Sci. Rep. 7, 14787.

117. Woodward, A. M., Mauris, J., and Argueso, P. (2013) J. Virol. 87, 5841-5847.

118. Levroney, E. L., Aguilar, H. C., Fulcher, J. A., Kohatsu, L., Pace, K. E., Pang, M., Gurney, K. B., Baum, L. G., and Lee, B. (2005) J. Immunol. $175,413-420$.

119. Yang, M. L., Chen, Y. H., Wang, S. W., Huang, Y. J., Leu, C. H., Yeh, N. C., Chu, C. Y., Lin, C. C., Shieh, G. S., Chen, Y. L., Wang, J. R., Wang, C. H., Wu, C. L., and Shiau, A. L. (2011) J. Virol. 85, 10010-10020.

120. Nita-Lazar, M., Banerjee, A., Feng, C., Amin, M. N., Frieman, M. B., Chen, W. H., Cross, A. S., Wang, L. X., and Vasta, G. R. (2015) Mol. Immunol. 65, 1-16. 
121. Farnworth, S. L., Henderson, N. C., Mackinnon, A. C., Atkinson, K. M., Wilkinson, T., Dhaliwal, K., Hayashi, K., Simpson, A. J., Rossi, A. G., Haslett, C., and Sethi, T. (2008) Am. J. Pathol. 172, 395-405.

122. Nita-Lazar, M., Mancini, J., Feng, C., González-Montalbán, N., Ravindran, C., Jackson, S., de Las Heras-Sánchez, A., Giomarelli, B., Ahmed, H., Haslam, S. M., Wu, G., Dell, A., Ammayappan, A., Vakharia, V. N., and Vasta, G. R. (2016) Dev. Comp. Immunol. 55, $241-252$.

123. Ahmed, H., Fink, N. E., and Vasta, G. R. (1994) Ann. N. Y. Acad. Sci. 712(1 Primordial Im), 318-320.

124. Kleshchenko, Y. Y., Moody, T. N., Furtak, V. A., Ochieng, J., Lima, M. F., and Villalta, F. (2004) Infect. Immun. 72, $6717-6721$.

125. Benatar, A. F., Garcia, G. A., Bua, J., Cerliani, J. P., Postan, M., Tasso, L. M., Scaglione, J., Stupirski, J. C., Toscano, M. A., Rabinovich, G. A., and Gómez, K. A. (2015) PLoS Negl. Trop. Dis. 9, e0004148.

126. Pelletier, I., Hashidate, T., Urashima, T., Nishi, N., Nakamura, T., Futai, M., Arata, Y., Kasai, K.-, Hirashima, M., Hirabayashi, J., and Sato, S. (2003) J. Biol. Chem. 278, 22223-22230.

127. van den Berg, T. K., Honing, H., Franke, N., van Remoortere, A., Schiphorst, W. E., Liu, F. T., Deelder, A. M., Cummings, R. D., Hokke, C. H., and van Die, I. (2004) J. Immunol. 173, 1902-1907.

128. Breuilh, L., Vanhoutte, F., Fontaine, J., van Stijn, C. M., Tillie-Leblond, I., Capron, M., Faveeuw, C., Jouault, T., van Die, I., Gosset, P., and Trottein, F. (2007) Infect. Immun. 75, 5148-5157.

129. Brand, C., Oliveira, F. L., Takiya, C. M., Palumbo, A. Jr., Hsu, D. K., Liu, F. T., Borojevic, R., Chammas, R., and El-Cheikh, M. C. (2012) Histol. Histopathol. 27, 1109-1120.

130. Debierre-Grockiego, F., Niehus, S., Coddeville, B., Elass, E., Poirier, F., Weingart, R., Schmidt, R. R., Mazurier, J., Guérardel, Y., and Schwarz, R. T. (2010) J. Biol. Chem. 285, 32744-32750.

131. Dunphy, J. L., Balic, A., Barcham, G. J., Horvath, A. J., Nash, A. D., and Meeusen, E. N. (2000) J. Biol. Chem. 275, $32106-32113$.

132. Young, A. R., Barcham, G. J., McWilliam, H. E., Piedrafita, D. M., and Meeusen, E. N. (2012) Vet. Immunol. Immunopathol. 145, 362-367.

133. Dunphy, J. L., Barcham, G. J., Bischof, R. J., Young, A. R., Nash, A., and Meeusen, E. N. (2002) J. Biol. Chem. 277, $14916-14924$.

134. Young, A. R., Barcham, G. J., Kemp, J. M., Dunphy, J. L., Nash, A., and Meeusen, E. N. (2009) Glycoconj. J. 26, 423-432.

135. Tasumi, S., and Vasta, G. R. (2007) J. Immunol. 179, 3086-3098.

136. Feng, C., Ghosh, A., Amin, M. N., Giomarelli, B., Shridhar, S., Banerjee, A., Fernández-Robledo, J. A., Bianchet, M. A., Wang, L. X., Wilson, I. B., and Vasta, G. R. (2013) J. Biol. Chem. 288, 24394-24409.

137. Feng, C., Ghosh, A., Amin, M. N., Bachvaroff, T. R., Tasumi, S., Pasek, M., Banerjee, A., Shridhar, S., Wang, L. X., Bianchet, M. A., and Vasta, G. R. (2015) Biochemistry 54, 4711-4730.

138. Chatterjee, A., Ratner, D. M., Ryan, C. M., Johnson, P. J., O’Keefe, B. R., Secor, W. E., Anderson, D. J., Robbins, P. W., and Samuelson, J. (2015) PLoS One 10, e0135340.

139. Okumura, C. Y., Baum, L. G., and Johnson, P. J. (2008) Cell. Microbiol. 10, 2078-2090.

140. Fichorova, R. N., Yamamoto, H. S., Fashemi, T., Foley, E., Ryan, S., Beatty, N., Dawood, H., Hayes, G. R., St-Pierre, G., Sato, S., and Singh, B. N. (2016) J. Biol. Chem. 291, 998-1013.

141. Kamhawi, S., Ramalho-Ortigao, M., Pham, V. M., Kumar, S., Lawyer, P. G., Turco, S. J., Barillas-Mury, C., Sacks, D. L., and Valenzuela, J. G. (2004) Cell 119, 329-341.

142. Valenzuela, J. G., Francischetti, I. M., Pham, V. M., Garfield, M. K., and Ribeiro, J. M. (2003) Insect Biochem. Mol. Biol. 33, 717-732.

143. Basseri, H. R., Tew, I. F., and Ratcliffe, N. A. (2002) Exp. Parasitol. 100, 226-234.

144. Huang, X., Tsuji, N., Miyoshi, T., Nakamura-Tsuruta, S., Hirabayashi, J., and Fujisaki, K. (2007) Glycobiology 17, 313-323.

145. Yoshino, T. P., Dinguirard, N., Kunert, J., and Hokke, C. H. (2008) Gene 411, 46-58.

146. Greenhalgh, C. J., Loukas, A., and Newton, S. E. (1999) Mol. Biochem. Parasitol. 101, 199-206.

147. Greenhalgh, C. J., Beckham, S. A., and Newton, S. E. (1999) Mol. Biochem. Parasitol. 98, 285-289.

148. Newlands, G. F., Skuce, P. J., Knox, D. P., Smith, S. K., and Smith, W. D. (1999) Parasitology 119, 483-490.

149. Fradin, C., Poulain, D., and Jouault, T. (2000) Infect. Immun. 68, 4391-4398.

150. Kohatsu, L., Hsu, D. K., Jegalian, A. G., Liu, F. T., and Baum, L. G. (2006) J. Immunol. 177, 4718-4726.

151. Jouault, T., El Abed-El Behi, M., Martinez-Esparza, M., Breuilh, L., Trinel, P. A., Chamaillard, M., Trottein, F., and Poulain, D. (2006) J. Immunol. 177, 4679-4687.

152. Jawhara, S., Thuru, X., Standaert-Vitse, A., Jouault, T., Mordon, S., Sendid, B., Desreumaux, P., and Poulain, D. (2008) J. Infect. Dis. 197, $972-$ 980.

153. Almeida, F., Wolf, J. M., da Silva, T. A., DeLeon-Rodriguez, C. M., Rezende, C. P., Pessoni, A. M., Fernandes, F. F., Silva-Rocha, R., Martinez, R., Rodrigues, M. L., Roque-Barreira, M. C., and Casadevall, A. (2017) Nat. Commun. 8, 1968.

154. Arthur, C. M., Baruffi, M. D., Cummings, R. D., and Stowell, S. R. (2015) Methods Mol. Biol. 1207, 1-35.

155. Vasta, G. R., Hunt, J. C., Marchalonis, J. J., and Fish, W. W. (1986) J. Biol. Chem. 261, 9174-9181.

156. Vasta, G. R., and Marchalonis, J. J. (1986) J. Biol. Chem. 261, 9182-9186.

157. Vasta, G. R. (2012) Adv. Exp. Med. Biol. 946, 21-36.

158. Vasta, G. R., Ahmed, H., Nita-Lazar, M., Banerjee, A., Pasek, M., Shridhar, S., Guha, P., and Fernández-Robledo, J. A. (2012) Front. Immunol. 3, 199.

159. Davicino, R. C., Elicabe, R. J., Di Genaro, M. S., and Rabinovich, G. A. (2011) Int. Immunopharmacol. 11, 1457-1463.

160. Baum, L. G., Garner, O. B., Schaefer, K., and Lee, B. (2014) Front. Immunol. 5, 284.

161. Medzhitov, R., and Janeway, C. A. Jr. (2000) Semin. Immunol. 12, 185-188, discussion, 257-344. 


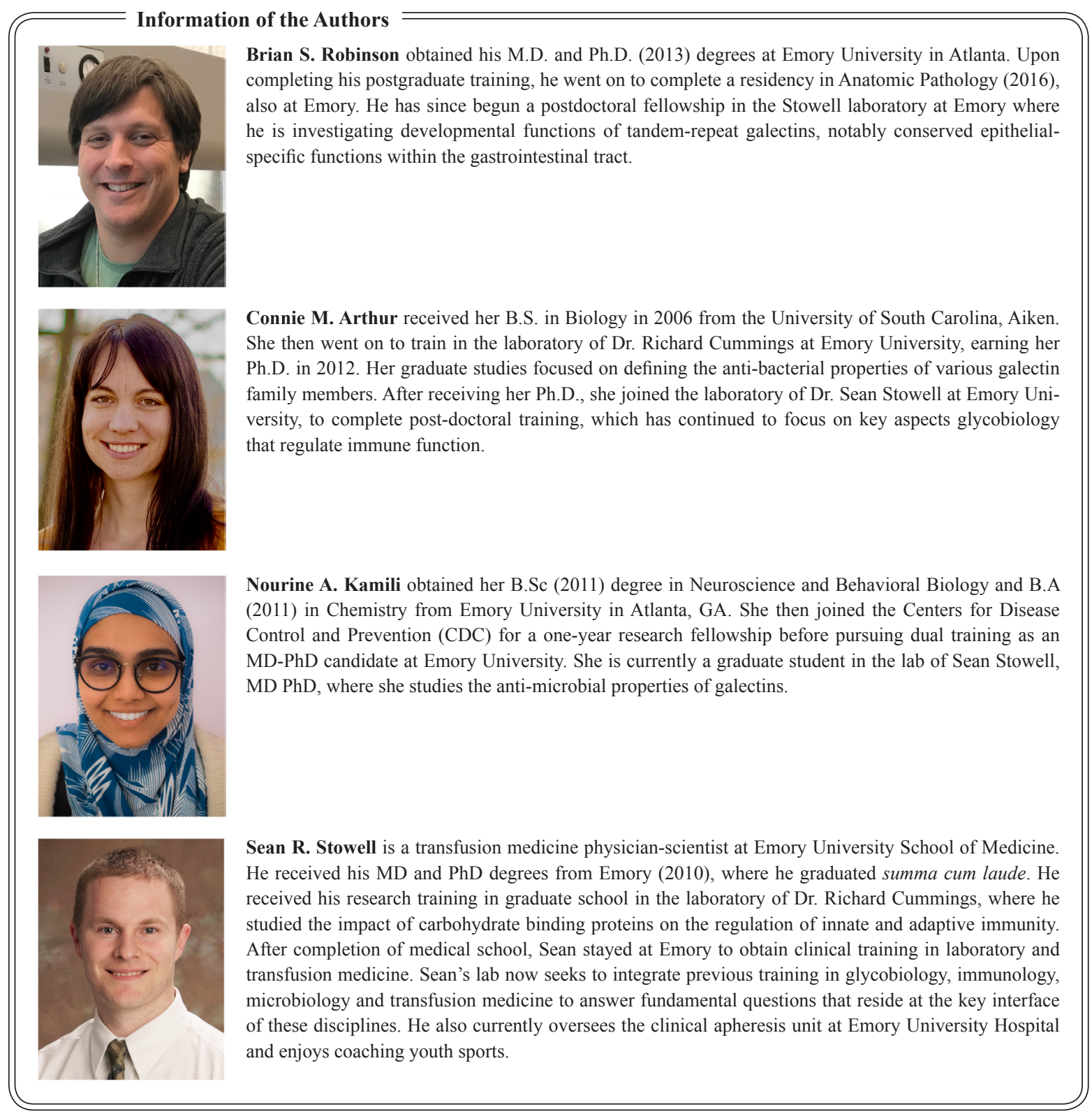

